\title{
Influência da irrigação e do genótipo na produção de castanha em cajueiro-anão-precoce ${ }^{(1)}$
}

\author{
Vitor Hugo de Oliveira(2), Levi de Moura Barros( ${ }^{(2)}$ e Raimundo Nonato de Lima ${ }^{(2)}$
}

\begin{abstract}
Resumo - Avaliou-se a influência da irrigação e do genótipo na produção de castanha em cajueiro-anãoprecoce (Anacardium occidentale L.) durante três anos. Foram estudados três clones (CP 09, CP 76 e CP 1001) e quatro regimes hídricos (testemunha sem irrigação e intervalos de irrigação de um, três e cinco dias). O delineamento experimental foi em blocos ao acaso, em parcelas subsubdivididas, com quatro repetições, com os regimes hídricos nas parcelas, os clones nas subparcelas, cada uma com quatro plantas, e os anos de produção nas subsubparcelas. A quantidade de água aplicada nos três tratamentos irrigados baseou-se na evaporação do tanque classe A. Em relação à produção de castanha, os clones de cajueiro-anão-precoce não apresentaram comportamento diferencial em resposta à irrigação; os clones CP 09 e CP 76 mostraram-se superiores ao CP 1001 quanto à estabilidade de safra; independentemente do regime hídrico estudado, o clone CP 76 mostrou-se menos produtivo do que os clones CP 09 e CP 1001.
\end{abstract}

Termos para indexação: Anacardium occidentale, regime hídrico do solo, produtividade, fenologia.

\section{Influence of irrigation and genotype on the nut production of precocious dwarf cashew}

\begin{abstract}
The influence of irrigation and genotype on the nut yield of tree dwarf cashew (Anacardium occidentale L.) was evaluated in a three-year trial. Three clones (CP 09, CP 76 and CP 1001) and four irrigation treatments (control - without irrigation, irrigation at one, three and five days interval) were studied. The experimental design was in randomized blocks, with split-split plots and four replications, irrigation levels in plots, clones in split-plot, each one with four plants, and years of production in splitsplit plots. The amount of water applied in three irrigated treatments was based on information from a class A evaporation pan. Concerning cashew nut production, cashew dwarf clones did not show a differentiation as to irrigation treatments; clones CP 09 and CP 76 showed better performance than CP 1001 on stability of nut production; clone CP 76, independently of irrigation treatments used, showed less productivity than clones CP 09 and CP 1001.
\end{abstract}

Index terms: Anacardium occidentale, soil water regimes, productivity, phenology.

\section{Introdução}

Historicamente, o cajueiro tem sido considerado uma planta resistente e adaptada à seca, sendo muitas vezes o único cultivo a produzir em condições extremamente adversas, o que provavelmente explica o desinteresse, expresso até recentemente, em verificar se a cultura responderia bem à irrigação

\footnotetext{
(1) Aceito para publicação em 12 de agosto de 2002.

Extraído da tese de doutorado apresentada pelo primeiro autor à Universidade Federal do Ceará, Fortaleza, CE.

${ }^{(2)}$ Embrapa-Centro Nacional de Pesquisa de Agroindústria Tropical, Caixa Postal 3761, CEP 60511-110 Fortaleza, CE. E-mail: vitor@cnpat.embrapa.br, levi@cnpat.embrapa.br, rlima@cnpat.embrapa.br
}

(Oliveira et al., 1998b). Em decorrência disso, a maioria das áreas cultivadas com o cajueiro existentes no Brasil foi implantada sob regime de sequeiro, com base na premissa de que a planta pode ser cultivada sob extrema adversidade hídrica (Oliveira et al., 1995).

Apesar da reduzida produtividade dos pomares de cajueiro comum (200 $\mathrm{kg} \mathrm{ha}^{-1}$ de castanha) e de anão-precoce ( $906 \mathrm{~kg} \mathrm{ha}^{-1}$ de castanha) (Pessoa et al., 2000) cultivados sob sequeiro, são escassos os estudos e as informações de pesquisa, em nível mundial, sobre irrigação nessa cultura.

Estudos preliminares revelaram produções de castanha de plantas de cajueiro-anão-precoce, sob irrigação localizada, superiores às do cajueiro culti- 
vado sob sequeiro (Saunders et al., 1995). Entretanto, a natureza e a dimensão da resposta da planta a distintos regimes hídricos ainda não foram quantificadas em termos dos caracteres produtivos. Tais resultados suprirão a demanda atual de um segmento de cajucultores que pretende se especializar, mediante o emprego da irrigação, na produção de pedúnculo de mesa, no período da entressafra, num primeiro instante, e, numa segunda fase, no aproveitamento total do pedúnculo na indústria de sucos e refrigerantes, doces, cajuína e outros derivados, além da perspectiva de maior produtividade de castanha (Oliveira et al., 1995).

O objetivo deste trabalho foi avaliar a produção de castanha dos clones de cajueiro-anão-precoce quando submetidos a diferentes regimes hídricos.

\section{Material e Métodos}

O trabalho foi realizado no Campo Experimental do Curu, da Embrapa-Centro Nacional de Pesquisa de Agroindústria Tropical, localizado no Município de Paraipaba, CE, latitude de $3^{\circ} 26^{\prime} \mathrm{S}$, longitude de $39^{\circ} 8^{\prime} \mathrm{W}$ e $31 \mathrm{~m}$ de altitude. A região apresenta tipo climático Bw da classificação de Köppen, com temperatura média anual de $28,1^{\circ} \mathrm{C}$ e precipitação pluvial média anual de $923,7 \mathrm{~mm}$, concentrada nos meses de janeiro a junho. Na Tabela 1 são apresentadas as principais características climáticas registradas durante a realização do experimento (Embrapa 1998a, 1998b, 1998c). O solo da área experimental pertence à unidade de mapeamento Podzólico Vermelho-Amarelo distrófico, A fraco, textura arenosa, fase caatinga litorânea, relevo plano.

Mudas enxertadas de cajueiro-anão-precoce, clones CP 09, CP 76 e CP 1001, foram plantadas em 21 de novembro de 1994, no espaçamento de 7,0x7,0 m e submetidas a quatro tratamentos: testemunha (sem irrigação), intervalo de irrigação de um dia, intervalo de irrigação de três dias e intervalo de irrigação de cinco dias. $\mathrm{O}$ delineamento experimental adotado foi em blocos ao acaso, com quatro repetições (uma planta/repetição), em parcelas subdivididas, em que os quatro regimes hídricos foram estudados nas parcelas e os três clones distribuídos espacialmente nas subparcelas, constituídas de quatro plantas.

O método de irrigação usado foi o de microirrigação, do tipo microaspersão, empregando-se um microaspersor autocompensante por planta, com vazão de $44 \mathrm{~L} \mathrm{hora}^{-1}$. $\mathrm{Na}$ determinação da quantidade de água aplicada em cada

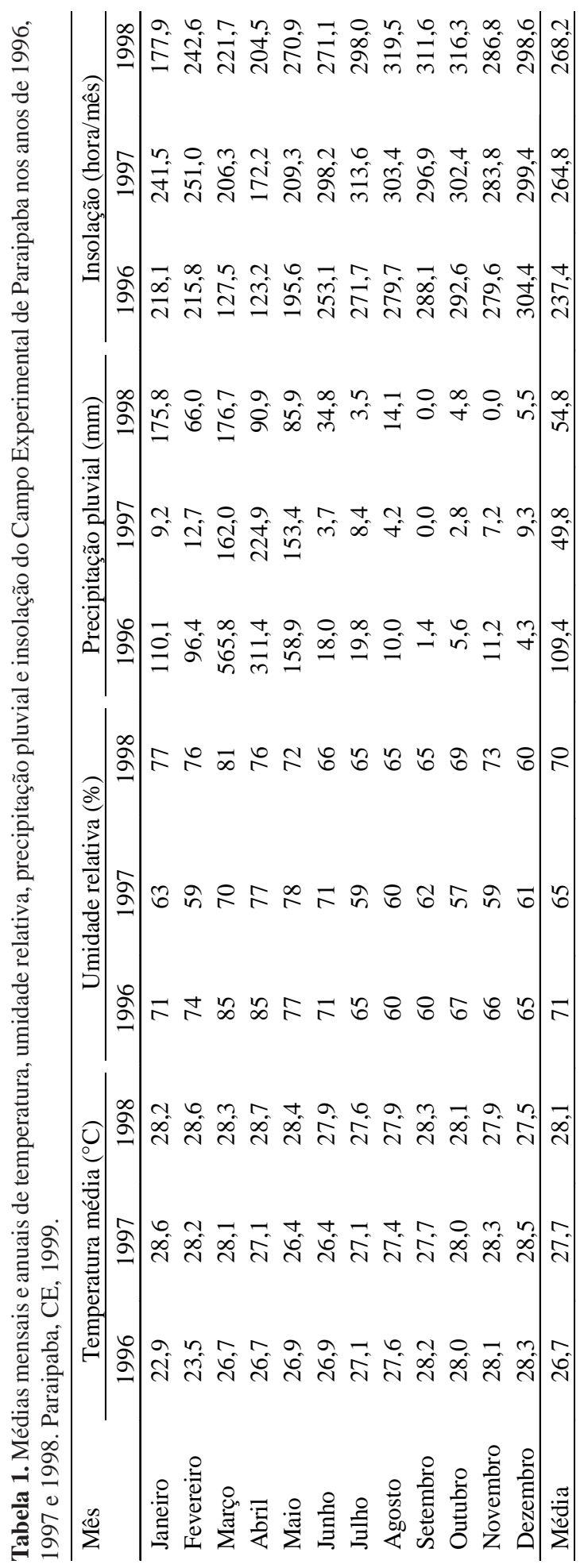


irrigação, nos diferentes tratamentos, utilizou-se a evaporação obtida no tanque classe $\mathrm{A}$ instalado nas imediações do experimento.

No cálculo das diferentes lâminas d'água empregadas, foram utilizadas as seguintes expressões:

$\mathrm{ET}_{\mathrm{C}}=\mathrm{ECA}_{\mathrm{x} \mathrm{K}} \times \mathrm{K}_{\mathrm{c}}$,

em que: $\mathrm{ET}_{\mathrm{C}}$ é a evapotranspiração de cultivo diária ( $\mathrm{mm}$ ); ECA é a evaporação diária do tanque classe A padrão (mm); $\mathrm{K}_{\mathrm{t}}$ é o coeficiente de tanque $(0,65)$, obtido a partir dos dados climáticos da região, segundo Doorenbos \& Pruitt (1984); e K $\mathrm{c}_{\mathrm{c}}$ é o coeficiente de cultivo, variável de acordo com a idade da planta, segundo Saunders et al. (1995): $1^{\circ}$ ano, $K_{c}=0,50 ; 2^{\circ}$ ano, $K_{c}=0,55 ; 3^{\circ}$ ano, $K_{c}=0,60$; $\mathrm{V}=(\mathrm{A} \times \mathrm{fc} \times \mathrm{ETc}) / \mathrm{EI}$, em que: $V$ é o volume aplicado por planta/dia, em litros; A é a área ocupada pela cultura $\left(\mathrm{m}^{2}\right)$; fc é o fator de cobertura (relação entre a área molhada e a área ocupada pela cultura: $0,15,0,30$ e 0,35 , respectivamente, em relação ao $1^{\circ}, 2^{\circ}$ e $3^{\circ}$ ano); EI é a eficiência de irrigação (\%).

As colheitas foram realizadas manualmente, três vezes por semana, durante o período de produção. Os frutos (castanhas), após colhidos, foram destacados dos pedúnculos e submetidos à pesagem, utilizando-se balança semi-analítica, obtendo-se, assim, a produção de cada planta ao longo do experimento. Os frutos com desenvolvimento fisiológico incompleto foram considerados refugos e não incluídos na pesagem.

Em 1996, foram aplicados $180 \mathrm{~g}$ de N/planta/ano (uréia) e $80 \mathrm{~g}$ de $\mathrm{K}_{2} \mathrm{O} /$ planta (cloreto de potássio) em parcelas mensais nas plantas irrigadas, via fertirrigação. $\mathrm{O} \mathrm{P}_{2} \mathrm{O}_{5}$ (superfosfato simples) foi aplicado no solo em dose única (80 g/planta/ano), no início do ano, junto com a primeira dose de $\mathrm{N}$ e de potássio.

Em 1997, foram aplicados $120 \mathrm{~g}$ de $\mathrm{P}_{2} \mathrm{O}_{5} /$ planta, e as adubações nitrogenada (200 g de N) e potássica (120 g de $\mathrm{K}_{2} \mathrm{O}$ /planta) passaram a ser feitas a cada 15 dias. Em 1998, empregou-se o mesmo critério de aplicação de fertilizantes dos anos anteriores, exceto quanto ao parcelamento da fertirrigação, que passou a ser semanalmente nos tratamentos irrigados, nas seguintes quantidades/planta: $200 \mathrm{~g}$ de $\mathrm{N}, 140 \mathrm{~g}$ de $\mathrm{P}_{2} \mathrm{O}_{5}$ e $160 \mathrm{~g}$ de $\mathrm{K}_{2} \mathrm{O}$. Como fonte de micronutrientes, foram aplicados anualmente em todos os tratamentos $50 \mathrm{~g}$ de FTE BR-12 por planta.

Nas plantas não irrigadas, nos três anos mencionados, as adubações foram feitas em cobertura, sob a projeção da copa da planta, parceladas em três vezes, durante o período chuvoso, mantendo-se as mesmas doses dos tratamentos irrigados.

Realizou-se uma análise conjunta, em parcelas subsubdivididas no tempo, para estudo do efeito dos três anos de avaliação sobre os regimes hídricos e clones. Os resultados de cada planta foram totalizados na estimação das variáveis estudadas. Na comparação das médias, utilizou-se o teste de Tukey a $5 \%$ e a $1 \%$ de probabi- lidade. Na verificação da homogeneidade de variâncias, todas as variáveis foram submetidas ao teste de Bartlett, que indicou ser desnecessária a transformação de quaisquer delas.

\section{Resultados e Discussão}

Os fatores clone e ano de colheita, isoladamente, e as interações clone $\mathrm{x}$ ano de colheita e ano de colheita x regime hídrico influenciaram significativamente a variável produção de castanha (Tabela 2). Não houve significância estatística em relação ao regime hídrico e em relação às interações entre regime hídrico $\mathrm{x}$ clone e ano de colheita $\mathrm{x}$ regime hídrico x clone.

Houve diferença estatística quanto à interação regime hídrico x ano de colheita em relação à variável produção de castanha. Enquanto em 1996 e 1997 não houve diferença estatisticamente significativa entre os valores médios de produção de castanha obtidos nos diferentes regimes hídricos, em 1998 os tratamentos submetidos à irrigação diferiram significativamente do tratamento não irrigado (Tabela 3 ). A idade das plantas pode ter contribuído para a reduzida resposta à irrigação no primeiro e no segundo ano, observando-se que no ano de instalação, a pluviosidade não determinou limitações ao desenvolvimento inicial das plantas, quer de sequeiro, quer

Tabela 2. Quadrados médios da análise de variância em relação à produção de castanha de caju em clones de cajueiro-anão-precoce submetidos a diferentes regimes hídricos. Paraipaba, CE, $1999^{(1)}$.

\begin{tabular}{lcc}
\hline Causa da variação & GL & $\begin{array}{c}\text { Quadrados } \\
\text { médios }\end{array}$ \\
\hline Bloco & 3 & $532.450,18^{\mathrm{ns}}$ \\
Regime hídrico & 3 & $725.867,95^{\mathrm{ns}}$ \\
Erro A (bloco x regime hídrico) & & $273.537,07$ \\
\hline Clone & 2 & $2.302 .643,12^{* *}$ \\
Regime hídrico x clone & 6 & $263.461,17^{\mathrm{ns}}$ \\
Erro B (bloco x clone (regime hídrico)) & & $266.323,26$ \\
\hline Ano de colheita & 2 & $2.010 .349,45^{* *}$ \\
Regime hídrico x ano de colheita & 6 & $267.973,36^{* *}$ \\
Clone x ano de colheita & 4 & $290.825,18^{* *}$ \\
Resíduo & 72 & $23.793,83$ \\
\hline
\end{tabular}

(1) Os coeficientes de variação em relação aos erros A, B e C foram 49,70\%, $49,04 \%$ e $14,66 \%$, respectivamente. ${ }^{n}$ Não-significativo. ${ }^{* * *}$ Significativo a $1 \%$ de probabilidade pelo teste $\mathrm{F}$. 
irrigadas. Nessa fase da vida da planta ocorre um maior investimento no crescimento vegetativo em detrimento do reprodutivo. Segundo Nambiar (1977), a elevada produtividade do cajueiro está associada ao crescimento vegetativo moderado das plantas.

Oliveira et al. (1996) e Crisóstomo et al. (1998) também constataram que os clones CP 09 e CP 76, respectivamente, não apresentaram diferença estatística em relação à variável produção de castanha.

$\mathrm{O}$ fator ano de colheita, por sua vez, influenciou significativamente a produção de castanha, observando-se no segundo e terceiro ano incrementos de $48,65 \%$ e $30,09 \%$, respectivamente, em relação ao primeiro ano (Tabela 3). A menor produção de castanha no primeiro ano de colheita já era esperada, pois a primeira frutificação do cajueiro-anão-precoce é pouco significativa. Contudo, ao contrário do previsto, observou-se uma redução média de $12,5 \%$ na produção do terceiro ano em relação ao segundo ano. Quando se comparam as produções obtidas nos tratamentos dentro do segundo e terceiro ano observa-se que esse decréscimo foi mais acentuado nas plantas cultivadas sob sequeiro (41,3\%), evidenciando a ação negativa de fatores climáticos sobre a produção no terceiro ano. Com efeito, a análise dos valores mensais de precipitação pluvial (Tabela 1) no período de máxima diferenciação floral e florescimento, que, segundo Frota \& Parente (1995), corresponde aos meses de junho a setembro, mostrou que a quantidade total de chuvas em 1997 (segundo ano) foi de apenas 16,3 mm, contra 52,4 mm no terceiro ano, equivalente a um acréscimo de $221,5 \%$. Esse aumento na pluviosidade pode ter con-

Tabela 3. Efeito da interação entre regime hídrico e ano de colheita na produção de castanha de caju. Paraipaba, CE, 1999(1).

\begin{tabular}{lrrrr}
\hline Regime hídrico $^{(2)}$ & 1996 & 1997 & 1998 & Média \\
\hline & ------------- & $\left(\mathrm{kg} \mathrm{ha}^{-1}\right)$ & -------------- \\
$\mathrm{A}$ & $803,36 \mathrm{a}$ & $1.129,35 \mathrm{a}$ & $663,03 \mathrm{~b}$ & $865,25 \mathrm{a}$ \\
$\mathrm{B}$ & $906,57 \mathrm{a}$ & $1.334,27 \mathrm{a}$ & $1.337,02 \mathrm{a}$ & $1.192,62 \mathrm{a}$ \\
$\mathrm{C}$ & $790,82 \mathrm{a}$ & $1.355,94 \mathrm{a}$ & $1.225,96 \mathrm{a}$ & $1.124,24 \mathrm{a}$ \\
$\mathrm{D}$ & $833,32 \mathrm{a}$ & $1.136,64 \mathrm{a}$ & $1.111,31 \mathrm{a}$ & $1.027,09 \mathrm{a}$ \\
\hline Média & $833,52 \mathrm{C}$ & $1.239,05 \mathrm{~A}$ & $1.084,33 \mathrm{~B}$ \\
\hline \\
${ }^{(1)}$ Médias seguidas pelas mesmas letras, minúsculas na vertical e maiús- \\
culas na horizontal, não diferem entre si pelo teste de Tukey a 5\% de pro- \\
babilidade. ${ }^{(2)}$ A: testemunha; B, C e D: intervalo de irrigação de um, três \\
e cinco dias, respectivamente.
\end{tabular}

tribuído para a queda de flores e frutos em início de desenvolvimento, afetando negativamente a produção. Venugopal \& Khader (1991) e Frota \& Parente (1995) afirmaram que o cajueiro necessita de uma estação seca para frutificar normalmente, já que a diferenciação floral ocorre quase sempre no final da estação chuvosa e o florescimento se processa durante os meses secos.

A interação clone $\mathrm{x}$ regime hídrico não foi estatisticamente significativa (Tabela 4). Em contraste com esses resultados, Oliveira et al. (1998a), em Mossoró, RN, com os mesmos clones sob condições de irrigação, sugerem que a resposta do cajueiro ao regime hídrico é dependente do genótipo. Vale destacar, entretanto, que esses autores trabalharam com plantas de idade mais avançada, aplicaram um maior volume de água por planta e tipo de irrigação diferente do empregado no presente trabalho que podem ter contribuído para os resultados obtidos. Isto demonstra a necessidade de novas pesquisas para investigar o comportamento fenológico dos diferentes genótipos quando submetidos a períodos intercalados de estresse hídrico e sob condições de manejo distintos.

Os clones CP 09 e CP 1001 apresentaram os maiores rendimentos médios, nos três anos, $52,97 \%$ e $34,31 \%$ superiores, respectivamente, ao CP 76 (Tabela 5). Comparando os valores médios de produção de castanha oriundos da interação clone $\mathrm{x}$ ano de colheita, constatou-se que no primeiro e segundo ano, o CP 09 e o CP 1001 foram superiores ao CP 76 quanto à produção de castanha e que no terceiro ano, o CP 09 destacou-se dos demais.

Quanto à estabilidade entre safras, os clones CP 09 e CP 76 mostraram-se superiores em relação ao

Tabela 4. Produção de castanha em clones de cajueiroanão-precoce sob diferentes regimes hídricos. Paraipaba, CE, 1999(1).

\begin{tabular}{|c|c|c|c|c|}
\hline Clon & A & B & $\mathrm{C}$ & $\mathrm{D}$ \\
\hline & \multicolumn{4}{|c|}{ - } \\
\hline & & 155011 & $1.330,59$ & $1.223,54$ \\
\hline & & & & \\
\hline CP 1001 & $1.110,40$ & $1.090,94$ & $1.093,14$ & $1.084,66$ \\
\hline
\end{tabular}

(1)A: testemunha; B, C e D: intervalo de irrigação de um, três e cinco dias, respectivamente; os dados representam médias de três anos. 
Tabela 5. Efeito da interação entre clones de cajueiro-anãoprecoce e ano de colheita na produção de castanha. Paraipaba, CE, 1999(1).

\begin{tabular}{lcrrr}
\hline Clone & 1996 & \multicolumn{1}{c}{1997} & \multicolumn{1}{c}{1998} & Média \\
\hline & $-----------------\left(\mathrm{kg} \mathrm{ha}^{-1}\right)------------------$ \\
CP 09 & $901,72 \mathrm{a}$ & $1.459,50 \mathrm{a}$ & $1.379,68 \mathrm{a}$ & $1.246,97 \mathrm{a}$ \\
CP 1001 & $991,16 \mathrm{a}$ & $1.320,83 \mathrm{a}$ & $972,37 \mathrm{~b}$ & $1.094,79 \mathrm{a}$ \\
CP 76 & $607,67 \mathrm{~b}$ & $936,82 \mathrm{~b}$ & $900,93 \mathrm{~b}$ & $815,15 \mathrm{~b}$ \\
\hline Média & $833,52 \mathrm{C}$ & $1.239,05 \mathrm{~A}$ & $1.084,33 \mathrm{~B}$ & \\
\hline
\end{tabular}

(1)Médias seguidas pelas mesmas letras, minúsculas na vertical e maiúsculas na horizontal, não diferem entre si pelo teste de Tukey a $1 \%$ de probabilidade.

CP 1001 (Tabela 5). Tal resultado pode ser atribuído à diferença de potencial genético entre os três clones estudados, claramente demonstrado na maior redução de produção do clone CP 1001 entre o segundo e terceiro ano, o que indica ser este genótipo mais afetado pela ocorrência de chuvas nas fases de diferenciação floral e frutificação do que o CP 09 e o CP 76. Comportamento similar foi observado por Oliveira et al. (1996), em Pacajus, CE, e Oliveira et al. (1998b), em Mossoró, RN. Embora o período de avaliação seja insuficiente para permitir inferências sobre uma possível tendência de alternância de produção durante o período experimental, este fato merece atenção e já foi mencionado por Almeida et al. (1998).

\section{Conclusões}

1. Em relação à produção de castanha, não existe comportamento diferencial dos clones de cajueiro-anão em resposta à irrigação.

2. Sob irrigação, os clones CP 09 e CP 76 apresentam maior estabilidade de produção entre safras em relação ao CP 1001.

3. O clone CP 76 é menos produtivo do que os clones CP 09 e CP 1001, independentemente do regime hídrico estudado.

\section{Referências}

ALMEIDA, F. A. G.; ALMEIDA, F. C. G.; MARTINS JÚNIOR, W.; MENESES JÚNIOR, J.; CARVALHO, P. R. de. Produtividade potencial de plantas enxertadas de cajueiro anão (Anacardium occidentale L.) em condições de irrigação. Revista Brasileira de Fruticultura, Cruz das Almas, v. 20, n. 3, p. 343-352, 1998.
CRISÓSTOMO, L. A.; OLIVEIRA, V. H.; MIRANDA, F. R.; ROSSETTI, A. G. Efeito de doses crescentes de nitrogênio e de potássio sobre a produtividade de cajueiro anão precoce (CP 76) sob regime de sequeiro e irrigado. Fortaleza: Embrapa-CNPAT, 1998. 5 p. (Pesquisa em Andamento, 28).

DOORENBOS, J.; PRUITT, W. O. Las necesidades de agua de los cultivos. Roma: FAO, 1984. 194 p. (Estudio FAO Riego y Drenaje, 24).

EMBRAPA. Centro Nacional de Pesquisa de Agroindústria Tropical (Fortaleza, CE). Boletim agroclimatológico 1996: Estação de Paraipaba, CE. Fortaleza: EmbrapaCNPAT/Funceme/DNOCS, 1998a. 13 p. (Boletim, 1).

EMBRAPA. Centro Nacional de Pesquisa de Agroindústria Tropical (Fortaleza, CE). Boletim agroclimatológico 1997: Estação de Paraipaba, CE. Fortaleza: EmbrapaCNPAT/Funceme/DNOCS, 1998b. 13 p. (Boletim, 2).

EMBRAPA. Centro Nacional de Pesquisa de Agroindústria Tropical (Fortaleza, CE). Boletim agroclimatológico 1998: Estação de Paraipaba, CE. Fortaleza: EmbrapaCNPAT/Funceme/DNOCS, 1998c. 13 p. (Boletim, 3).

FROTA, P. C. E.; PARENTE, J. I. G. Clima e fenologia. In: ARAÚJO, J. P. P.; SILVA, V. V. (Org.). Cajucultura: modernas técnicas de produção. Fortaleza: EmbrapaCNPAT, 1995. p. 43-54.

NAMBIAR, M. C. Cashew. In: ALVIM, P. T.; KOZLOWSKI, T. T. (Ed.). Ecophysiology of tropical crops. New York: Academic, 1977. p. 461-477.

OLIVEIRA, V. H.; CRISÓSTOMO, L. A.; MIRANDA, F. R. de; ALMEIDA, J. H. S. Produtividade de clones comerciais de cajueiro anão precoce (Anacardium occidentale L.) irrigados no Município de Mossoró RN. Fortaleza: Embrapa-CNPAT, 1998a. 6 p. (Comunicado Técnico, 14).

OLIVEIRA, V. H.; MIRANDA, F. R. de; SANTOS, F. J. S.; SAUNDERS, L. C. U. Distribuição mensal da produção de castanha de clones comerciais de cajueiro anão precoce (Anacardium occidentale L.) irrigados no Ceará: 1 ano. Fortaleza: Embrapa-CNPAT, 1998b. 4 p. (Pesquisa em Andamento, 22).

OLIVEIRA, V. H.; PARENTE, J. I. G.; SAUNDERS, L. C. U. Irrigação em cajueiro anão precoce: uma perspectiva promissora. Revista Frutar, Fortaleza, v. 1, n. 1, p. 4$5,1995$.

OLIVEIRA, V. H.; SAUNDERS, L. C. U.; PARENTE, J. I. G.; ALMEIDA, J. I. L.; MONTENEGRO, A. A. T. Comportamento do cajueiro comum e anão precoce 
submetidos a diferentes tensões de água no solo. Fortaleza: Embrapa-CNPAT, 1996. 4 p. (Pesquisa em Andamento, 19).

PESSOA, P. F. A. P.; OLIVEIRA, V. H.; SANTOS, F. J. S.; SEMRAU, L. A. S. Análise da viabilidade econômica do cultivo do cajueiro irrigado e sob sequeiro. Revista Econômica do Nordeste, Fortaleza, v. 31, n. 2, p. 178-187, 2000.
SAUNDERS, L. C. U.; OLIVEIRA, V. H.; PARENTE, J. I. G. Irrigação em cajueiro anão precoce. Fortaleza: Embrapa-CNPAT, 1995. 28 p. (Documentos, 16).

VENUGOPAL, K.; KHADER, K. B. Effect of soil and climate on the productivity of cashew. Indian Cashew Journal, Cochin, v. 20, p. 19-24, 1991. 